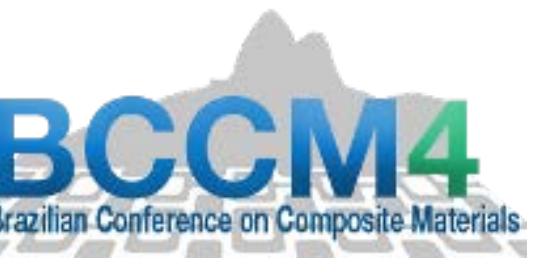

\title{
ECO-FRIENDLY SODIUM BICARBONATE TREATMENT AND ITS EFFECT ON EPOXY/POLYESTER COIR FIBRE COMPOSITES
}

\author{
Lívia Á. de Oliveira ${ }^{(1,2)}$, Júlio C. dos Santos ${ }^{(1,2)}$, Luciano M. Gomes Vieira ${ }^{(3)}$, Valdir \\ Mano $^{(2)}$, Rodrigo S. Freire ${ }^{(1,2)}$, Túlio H. Panzera ${ }^{(1,2)}$
}

(1) Centre for Innovation and Technology in Composite Materials - CIT ${ }^{\mathrm{e}}$, Department of Mechanical Engineering, Federal University of São João del Rei-UFSJ, Brazil.

(2) Department of Natural Sciences, Federal University of São João del Rei-UFSJ, Brazil.

(3) Department of Production Engineering, Federal University of Minas Gerais-UFMG, Brazil.

https://doi.org/10.21452/bccm4.2018.10.04

\begin{abstract}
This work evaluates a new eco-friendly coir fibre surface treatment method based on sodium bicarbonate $\left(\mathrm{NaHCO}_{3}\right)$ solution. The fibres were treated with $10 \mathrm{wt} \% \mathrm{NaHCO}_{3}$ solution at different periods (24, 96 and $168 \mathrm{~h}$ ). A full factorial design $2^{1} 4^{1}$ was established to investigate the effect of the type of matrix (epoxy and polyester) and treatment time (24, 96 and $168 \mathrm{~h}$ ) on the mechanical properties of coir fibre composites. Single fibre tensile test revealed a gradual increase in elastic modulus attributed to the treatment time factor. Epoxy and polyester composites led to higher strength and stiffness, respectively, in both tensile and flexural tests. The alkaline treatment did not affect the mechanical strength of the composites. Enhanced tensile and flexural moduli were obtained when the treatment time increased at 96 or 168 hours levels. Finally, the proposed treatment proved to be feasible and efficient in increasing the stiffness of coir fibre composites, besides being less damaging to the environment after disposal.
\end{abstract}

Keywords: sodium bicarbonate, coir fibre, epoxy, polyester, mechanical properties.

\section{INTRODUCTION}

Over the past decades, plant fibres including flax, hemp, jute, sisal, coir, kenaf and many others, have been receiving significant attention as reinforcing materials due to their advantages over synthetic fibres such as low cost, low density, biodegradability, renewability and considerate mechanical performance [1-7]. Composites made from natural fibres have been designed for extensive applications in areas such as consumer goods, civil structure, packaging, sports, automobiles and other mass production industries [8-10].

Among the numerous natural fibres, coir is an abundant, versatile, renewable, cheap and biodegradable lignocellulosic fibre extracted from coconut fruit (Cocos nucifera), which is extensively cultivated in tropical regions [11-13]. In addition to conventional uses of coir 
fibre as cordage, cushion, floor-furnishing, mats, carpets, ropes, etc. [14-17], this natural raw material has shown great potential in the composite field due to its several valuable properties such as resilience, rigidity, wettability, elongation at break and resistance to weathering [17].

The main drawback of using natural fibre as reinforcement in polymeric composites is the incompatibility between the hydrophilic nature of the fibre and the hydrophobic nature of the matrix [18-21]. These features lead to poor fibre-matrix adhesion and undesirable mechanical properties to the material as a result of the low ability to transfer stress from the matrix to the fibre [22]. To overcome this problem, it is necessary to modify the surface of the fibres, either by physical or chemical methods [14].

Among methods for improving the adhesive character of the natural fibre, alkali treatment can be considered the most widely used technique because of its effectiveness in modifying the fibre surface, increasing the interfacial bond strength between the fibre and the matrix [2224]. However, incorrect disposal of the chemical waste after treatment may be harmful to the environment [25]. In relation to this, a simple, economical and eco-friendly correct treatment, based on the use of an aqueous solution of sodium bicarbonate, was proposed by Fiore et al. [25], revealing remarkable improvements in the mechanical properties of the treated fibres and composites.

Based on the previous literature, this work investigates the effect of this eco-friendly sodium bicarbonate treatment on the properties of coir fibres in different treatment times through physical (density), mechanical (tensile) and microstructural (SEM) analyses. In addition, a design of experiment will be conducted to evaluate the compatibility of these fibres in epoxy and polyester polymers, through morphological analyses and tensile, flexural and Charpy impact tests.

\section{MATERIALS AND METHODS}

\subsection{Materials}

The composite materials were composed of two distinct polymer matrices: (i) unsaturated orthoftalic polyester resin/methyl-ethyl-ketone hardener (2 wt.\%), supplied by Reichold, and (ii) Renlam M epoxy resin/Aradur HY956 hardener (5:1), supplied by Huntsman. The reinforcement phase consists of short coir fibres, supplied by Deflor Bioengenharia (Belo Horizonte - Brazil). Sodium bicarbonate $\left(\mathrm{NaHCO}_{3}, 99 \%\right)$ was supplied by Synth (Brazil). The treatment process of the fibres was similar to that reported by Fiore et al. [25]. Portions of coir fibres were soaked in 10 wt.\% $\mathrm{NaHCO}_{3}$ solution for 24, 96 and 168 hours at room temperature $\left(\sim 20^{\circ} \mathrm{C}\right)$ into a sealed vessel, then immersed in fresh water for $30 \mathrm{~min}$ (without acid neutralization) and oven dried at $50{ }^{\circ} \mathrm{C}$ for 24 hours.

\subsection{Statistical design}

A full factorial design $2^{1} 4^{1}$ was established to investigate the effect of matrix type (epoxy; polyester) and treatment time (0 h; $24 \mathrm{~h} ; 96 \mathrm{~h}$ and $168 \mathrm{~h}$ ) on the tensile, flexural and impact properties of the composites, resulting in 8 experimental conditions (E.C.) (see Table 1). In replicate 1 , thirty specimens (ten for each mechanical testing) were fabricated for each experimental condition. Two replicates were considered, running a total of 480 specimens. The statistical software Minitab v. 17 was used to perform the Design of Experiment (DoE) and Analysis of Variance (ANOVA) techniques.

Table 1. Full factorial design $\left(2^{1} 4^{1}\right)$.

\begin{tabular}{ccc|ccc}
\hline E.C. & Matrix Phase & Treatment Time & E.C. & Matrix Phase & Treatment Time \\
\hline 1 & Epoxy & $0 \mathrm{~h}$ & 5 & Polyester & $0 \mathrm{~h}$ \\
2 & Epoxy & $24 \mathrm{~h}$ & 6 & Polyester & $24 \mathrm{~h}$
\end{tabular}


$4^{\text {th }}$ Brazilian Conference on Composite Materials. Rio de Janeiro, July $22^{\text {nd }}-25^{\text {th }}$, 2018

\begin{tabular}{ccc|ccc}
3 & Epoxy & $96 \mathrm{~h}$ & 7 & Polyester & $96 \mathrm{~h}$ \\
4 & Epoxy & $168 \mathrm{~h}$ & 8 & Polyester & $168 \mathrm{~h}$ \\
\hline
\end{tabular}

\subsection{Characterization}

The fibre microstructure was characterized by scanning electron microscopy (SEM) Hitachi T-3000.

The tensile properties of the fibres were determined following the recommendations of ASTM D3822-14 [25]. A single fibre was glued onto a paper and clamped on a universal testing machine. A constant cross-section was assumed for the estimation of tensile properties under a test speed of $2 \mathrm{~mm} / \mathrm{min}$. Fifteen samples for each treatment condition (0;24; 96 and $168 \mathrm{~h}$ ) were tested. The apparent density test of the coir fibres followed the principle of Archimedes and ASTM D276-12 [26].

The polyester and epoxy matrix phases were characterized via tensile, flexural and Charpy impact tests, conducted according to ASTM D638-14 [27], ASTM D790-15 [28] and ASTM D6110-10 [29], respectively. Five samples of each experimental condition were fabricated for each test and replicate. Two replicates were considered in the experiment.

The tensile and flexural properties of the composites were determined according to ASTM D3039/3039M [30] and ASTM D790-15 [28], respectively. The tests were conducted at 2 $\mathrm{mm} / \mathrm{min}$ using a Shimadzu AG-X Plus testing machine, equipped with a $100 \mathrm{kN}$ capacity load cell. The impact tests were performed on a Charpy Impact Tester XJJ Series, following the recommendations of ASTM D6110-10 [29]. A scanning electron microscopy (SEM) analyses was used to observe the microstructure of the composite cross section after the Charpy impact test.

\subsection{Manufacturing process}

The composites were manufactured via hand lay-up and cold uniaxial compaction, as shown in Figure 1a. The aluminium sheet $(300 \mathrm{~mm}$ x $300 \mathrm{~mm}$ ) covered with a thin layer of wax as the release agent was placed into a metallic mould. Subsequently, short coir fibres $(30 \% \mathrm{v} / \mathrm{v})$ were weighted according to the required grammage $\left(900 \mathrm{~g} / \mathrm{m}^{2}\right)$ and randomly distributed into the mould. The polymeric matrix ( $70 \% \mathrm{v} / \mathrm{v})$ was prepared by hand-mixing the resin and the hardener for 5 minutes at room temperature, and then spread uniformly over the coir fibres. Another aluminium sheet, covered with wax, was placed on top and the mould was closed with a lid. A pressure of $654 \mathrm{kPa}$ was applied for 12 hours in room temperature. Subsequently, the composite was released from the mould (Figure 1b) and sealed with a plastic bag to prevent moisture absorption for 14 days post-cure. Finally, the composite plate was cut according to the recommendations of ASTM standards and tested.

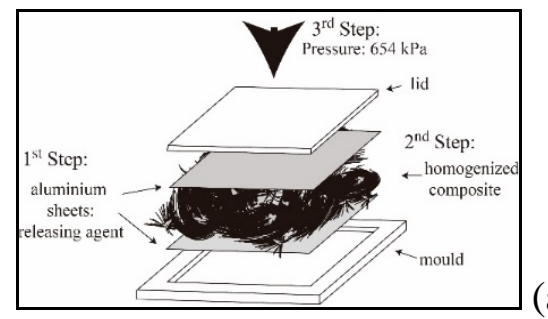

(a)

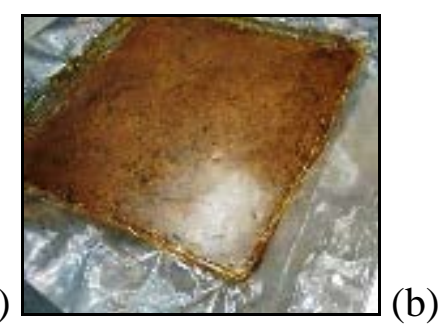

Figure 1. Manufacturing process: (a) cold compaction mechanism (b) composite plate.

\section{RESULTS AND DISCUSSION}

\subsection{Coir fibre characterization}

Table 2 shows the mean physical and mechanical properties of coir fibres at different treatment times. It is possible to note that the apparent density increased with longer treatment 
time. The $\mathrm{Na}^{+}$ions, released in the sodium bicarbonate solution, has a favourable diameter to widen the smallest pores in between the lattice planes and penetrate into them, which contributes to increase the apparent density [31, 32]. The rearrangement of cellulose fibrils, created by new hydrogen bonds between the chain, is attributed to the removal of hemicellulose, lignin and waxy substances to the external surface of the fibre [25, 33]. However, according to the SEM images shown in Figure 2, there was no significant change in the fibre surface roughness, evidencing that the sodium bicarbonate treatment is not very strong.

The mechanical properties of coir fibres are presented in a data range (Table 2), being attributed to the non-uniformity of this natural product. The tensile strength was not affected by treatment time factor. Otherwise, the modulus of elasticity presented a significant increase, as shown in Figure 3, which is attributed to the cellulose fibrils rearrangement, causing a decrease in the spiral angle and an increase in the molecular orientation [31].

Table 2. Coir fibre properties.

\begin{tabular}{lcccc}
\hline \multirow{2}{*}{ Property } & \multicolumn{4}{c}{ Treatment Time } \\
\cline { 2 - 5 } & $0 \mathrm{~h}$ & $24 \mathrm{~h}$ & $96 \mathrm{~h}$ & $168 \mathrm{~h}$ \\
\hline Apparent Density $\left(\mathrm{g} / \mathrm{cm}^{3}\right)$ & $0.83 \pm 0.02$ & $1.01 \pm 0.02$ & $1.02 \pm 0.03$ & $1.04 \pm 0.03$ \\
Tensile Strength $(\mathrm{MPa})$ & $59-297$ & $60-242$ & $45-231$ & $83-224$ \\
Modulus of Elasticity $(\mathrm{GPa})$ & $3.2-4.3$ & $3.3-5.1$ & $3.9-6.9$ & $4.1-8.8$ \\
\hline
\end{tabular}

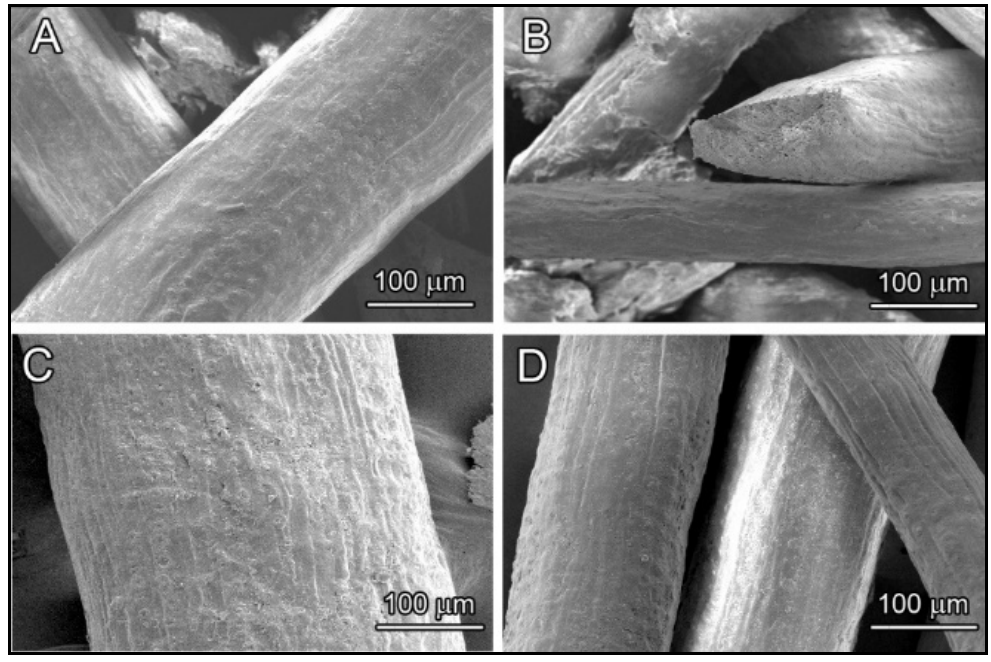

Figure 2. Coir fibre scanning electron micrographs at different treatment times: (A) 0 h, (B) $24 \mathrm{~h}$, (C) $96 \mathrm{~h}$ and (D) $168 \mathrm{~h}$. 


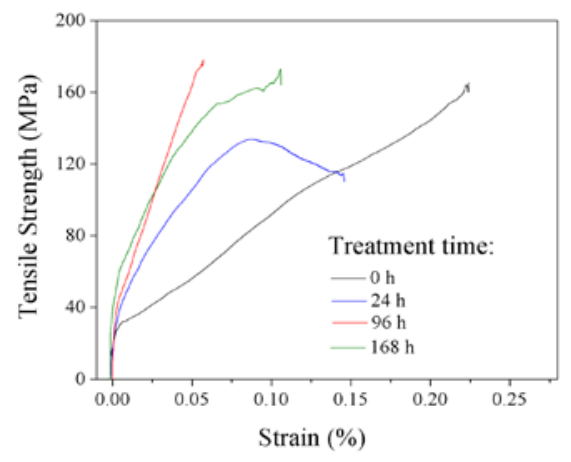

(a)

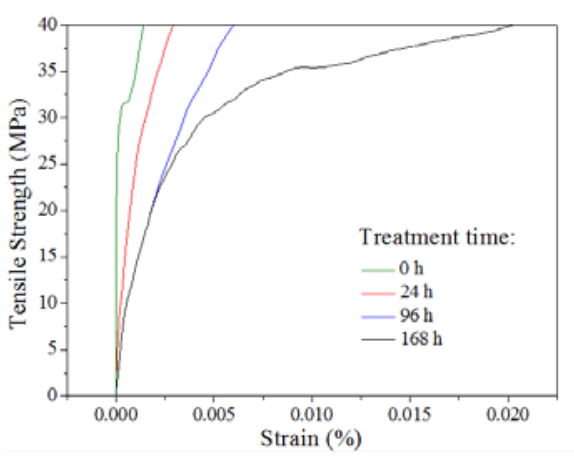

Figure 3. (a) Tensile testing of single filament of coir fibre, (b) Image zoom.

\subsection{Matrix characterization}

Table 3 shows the mechanical properties of the matrix phases in pristine conditions. It is noteworthy that the epoxy polymer is superior in strength, while the polyester is superior in modulus. The higher stiffness of the polyester polymer reflects on a lower impact resistance as shown in Table 3.

Table 3. Mechanical properties of the matrices.

\begin{tabular}{cccc}
\hline \multirow{2}{*}{ Property (Unit) } & \multicolumn{2}{c}{ Type of Matrix } \\
\cline { 3 - 4 } & & Epoxy & Polyester \\
\hline \multirow{2}{*}{ Tensile } & Strength $(\mathrm{MPa})$ & $47.29( \pm 2.02)$ & $39.80( \pm 3.05)$ \\
& Modulus $(\mathrm{GPa})$ & $2.24( \pm 0.11)$ & $2.44( \pm 0.14)$ \\
\hline \multirow{2}{*}{ Flexural } & Strength $(\mathrm{MPa})$ & $69.26( \pm 3.96)$ & $55.85( \pm 2.91)$ \\
& Modulus $(\mathrm{GPa})$ & $2.14( \pm 0.04)$ & $2.19( \pm 0.08)$ \\
\hline \multirow{2}{*}{ Impact } & Resistance $\left(\mathrm{kJ} / \mathrm{m}^{2}\right)$ & $8.72( \pm 1.41)$ & $5.81( \pm 0.31)$ \\
\hline
\end{tabular}

\subsection{Composite design}

Table 4 presents the DoE/ANOVA analysis. Significant effects (P-value $\leq 0.05)$ are underlined while those highlighted in bold will be interpreted via effect plots, which illustrate statistical analysis and provide variation of factors and levels. The $\mathrm{R}^{2}$-adj values, ranging from 93.23\% to $99.89 \%$, indicate models of high predictive ability since they are close to $100 \%$.

ANOVA was validated by the Anderson-Darling normality test, which exhibits P-values higher than $0.05(0.145-0.999)$, implying that the data follow a normal distribution.

Table 4. Analysis of variance (ANOVA).

\begin{tabular}{|c|c|c|c|c|c|c|}
\hline \multicolumn{2}{|r|}{ ANOVA } & \multicolumn{5}{|c|}{ P-value $\leq 0.05$} \\
\hline & Experimental Factors & $\begin{array}{c}\text { Tensile } \\
\text { Strength } \\
\text { (MPa) }\end{array}$ & $\begin{array}{c}\text { Tensile } \\
\text { Modulus } \\
\text { (GPa) }\end{array}$ & $\begin{array}{c}\text { Flexural } \\
\text { Strength } \\
\text { (MPa) }\end{array}$ & $\begin{array}{c}\text { Flexural } \\
\text { Modulus } \\
\text { (GPa) }\end{array}$ & $\begin{array}{c}\text { Impact } \\
\text { Resistance } \\
\left(\mathrm{kJ} / \mathrm{m}^{2}\right)\end{array}$ \\
\hline \multirow{2}{*}{ 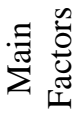 } & Matrix Phase & $\underline{0.000}$ & $\underline{0.000}$ & $\underline{0.000}$ & $\underline{0.000}$ & $\underline{0.000}$ \\
\hline & Treatment Time & $\underline{0.020}$ & $\underline{0.000}$ & 0.046 & $\underline{0.000}$ & $\underline{0.020}$ \\
\hline \multirow[t]{2}{*}{ 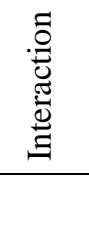 } & Matrix Phase x Treatment Time & $\underline{0.047}$ & $\underline{0.003}$ & 0.412 & 0.148 & $\underline{0.013}$ \\
\hline & $\mathrm{R}^{2}$ - adj & $98.98 \%$ & $97.19 \%$ & $93.23 \%$ & $96.87 \%$ & 99.89\% \\
\hline
\end{tabular}


Anderson-Darling $(\mathrm{P} \geq 0.05)$

0.145

0.824

0.551

0.606

0.999

\subsubsection{Tensile test}

Tensile strength data varied from 12.40 MPa to $18.77 \mathrm{MPa}$, while tensile modulus ranged from 2.32 GPa to $3.05 \mathrm{GPa}$, as shown in Figure 4, items a and b, respectively. As noted, coir fibres led to an increase in tensile modulus and a reduction in tensile strength compared to the neat polymer properties. The increased stiffness is attributed to the coir fibre characteristics, while the reduced strength is relative to the short length and the random orientation of thereof, which hinders the load distribution throughout the sample [25,34,35].

Figure 4, items c and d, shows the second order interaction effect plots for the tensile properties. The letters in blue represent the Tukey's comparison test, in which similar letters belong to the same grouping, i.e., equivalent means. Composite materials made with epoxy matrix phase present higher tensile strength (41.68\%), as shown in Figure 4c. In contrast, polyester composites achieved higher tensile moduli (Figure 4d). These results are in accordance to the matrix characterization (Table 3). The strength is largely affected by fibre orientation and fibre-matrix interfacial adhesion [25,34]. Thus, higher strength values indicate that coir fibres have better compatibility with epoxy matrix composites.

The chemical treatments did not affect the tensile strength of the polyester composites, as observed by the same grouping A in the Tukey's test (see Figure 4c). A slight increase of 6\% in tensile strength was obtained for epoxy composites when considering 96 hours of treatment. This behaviour can be attributed to a poor increase in surface roughness after treatment (see Figure 2), affecting physical fibre/matrix adhesion, as evidenced by the fibre pull-out mechanism of the fractured surface (Figure 5 - black arrows) especially when polyester matrix was considered. An opposite behaviour was observed for tensile modulus since this response is measured in small deformations, which are not affected by interfacial adhesion [25]. A gradual enhancement in composite stiffness is revealed in Figure 4d as treatment time increases. This effect is in agreement with the fibre characterization (see Table 2), where the longer treatment time led to a higher stiffness of the fibre and composite.
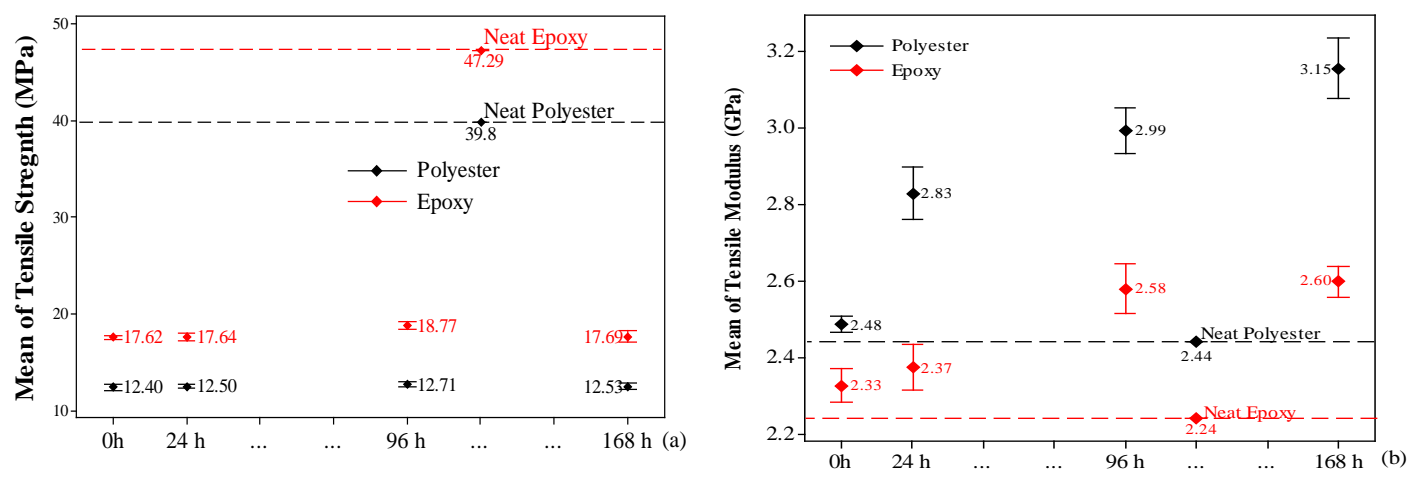

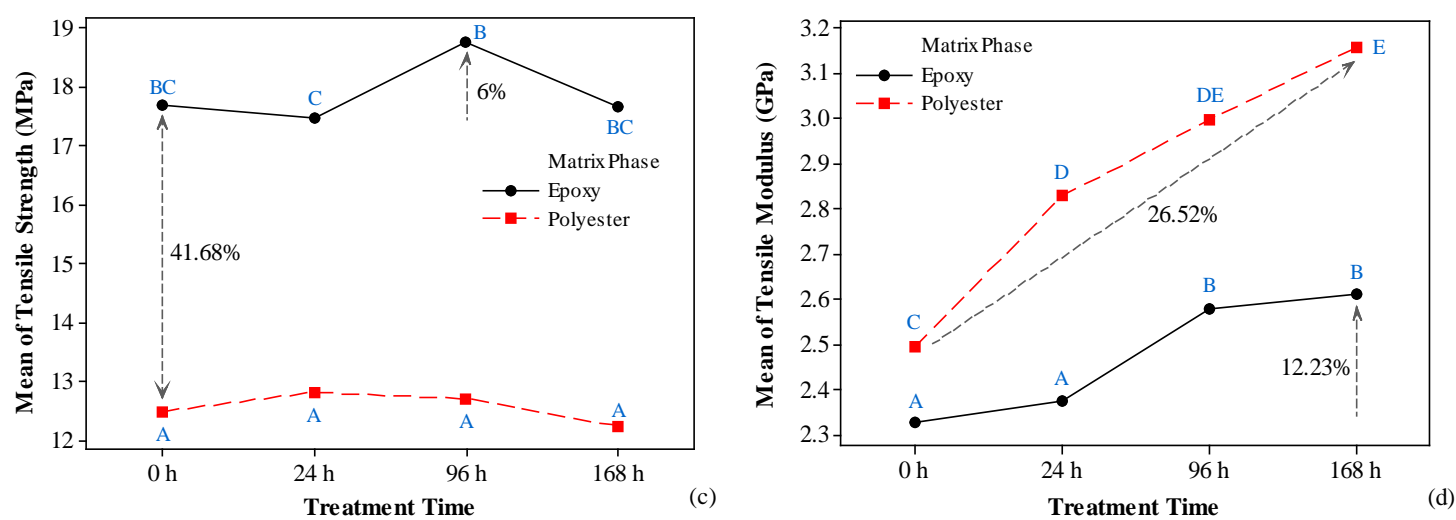

Figure 4. Tensile properties of coir fibre composites: (a) strength and (b) modulus. Second order interaction effect plot for the mean tensile (c) strength and (d) modulus.

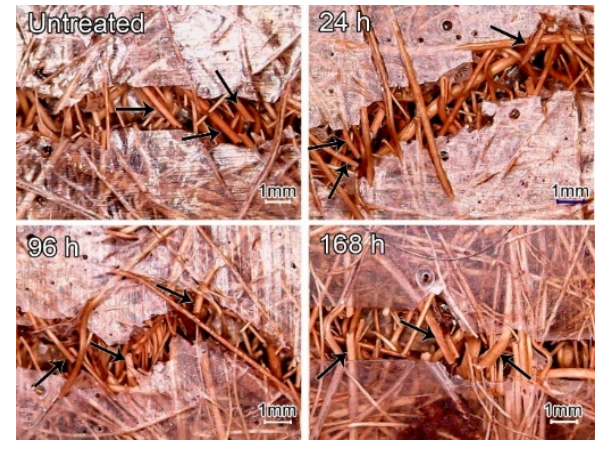

Figure 5. Fracture surface of the polyester matrix composite.

\subsubsection{Flexural test}

The flexural strength data varied from 24.73 MPa to 40.44 MPa, while the flexural moduli ranged from 2.27 GPa to $2.78 \mathrm{GPa}$, as shown in Figure 6, items a and b, respectively. Coir fibre reinforced polymers achieved higher flexural modulus and lower flexural strength compared to pure polymers. The similar effect was also identified for tensile properties, being attributed to the intrinsic characteristics of the coir fibres.

Figure 6, items $\mathrm{c}$ and $\mathrm{d}$, shows the main effect plot for the flexural test. The epoxy composites presented higher strength (45.33\%) and lower stiffness (-5.14\%) in comparison to the polyester composites. These results are in accordance to the matrix characterization (see Table 3), implying that the matrix phase plays a role in the composite mechanical properties, in addition to that the epoxy polymer offers a better compatibility with the coir fibres [20,36].

The highest flexural modulus (Figure 6d) was reached for composites made with polyester matrix phase and treated coir fibres at $96 \mathrm{~h}$ or $168 \mathrm{~h}$. This behaviour, also reported for tensile test, is attributed to the increase of coir fibre stiffness after treatment (see Table 2).
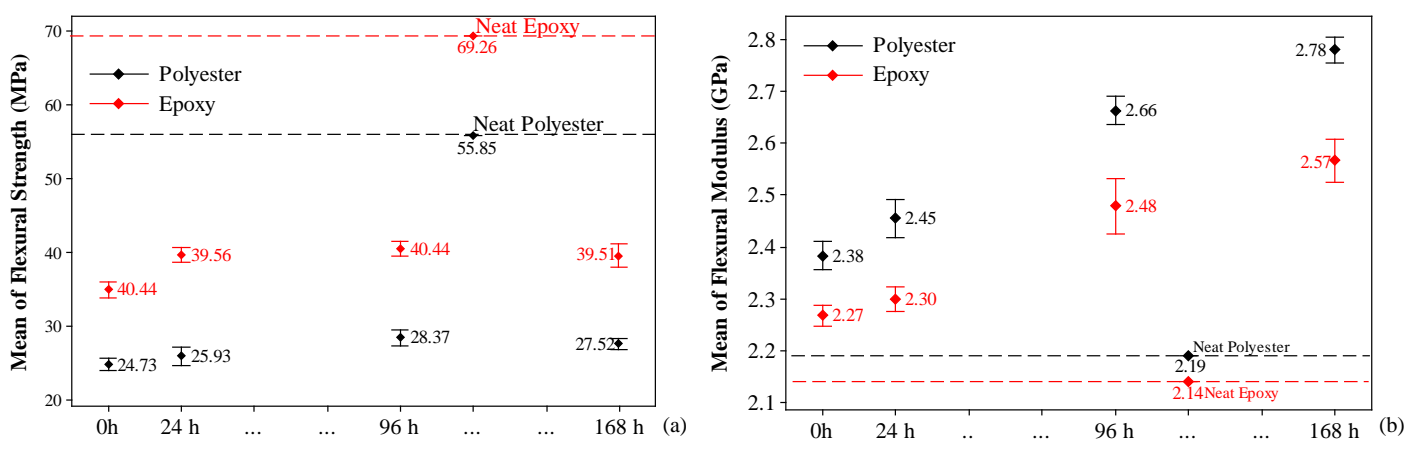

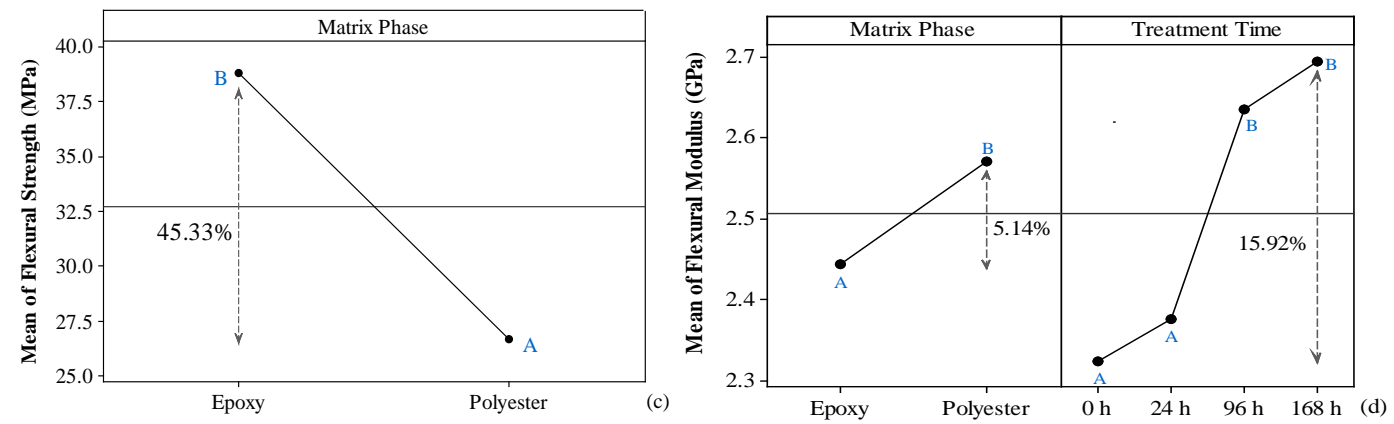

Figure 6. Flexural properties of coir fibre composites: (a) strength and (b) modulus. Main effect plot for flexural: (c) strength and (d) modulus.

\subsubsection{Impact test}

Figure 7a presents the impact resistance of the composites, which varied from $6.04 \mathrm{~kJ} / \mathrm{m}^{2}$ to $18.03 \mathrm{~kJ} / \mathrm{m}^{2}$. Although the polyester polymer has achieved low energy absorption, as shown in Table 3 and Figure 7a, an opposite behaviour was obtained for coir fibre reinforced composites, revealing a percent increase nearly at $194 \%$ in comparison to the neat polyester resin (Figure $7 \mathrm{a}$ ). A substantial variation of $198 \%$ was identified between epoxy and polyester composites (Figure 7b). The impact resistance is largely affected by the level of bonding. While a significant part of the energy absorption during impact takes place through the fibre pull-out mechanism, very strong interfaces have a detrimental effect on the impact properties [37]. Thus, the high impact resistance achieved by the polyester composites can be attributed to the poor compatibility between the fibre and the matrix, resulting in a fibre pull-out mechanism, evidenced by SEM images obtained for the composite cross-section (Figure 8a).

The lower impact resistance obtained for epoxy composites (Figure 7a-b) is due to better fibre-matrix adhesion, resulting in a fibre fracture (Figure 8b) in the crack-plane with low fibre pull-out and, consequently, a reduction in energy dissipation [37-39].

The treatment time factor did not affect the impact resistance of the composites, as observed in Figure $7 \mathrm{~b}$ by the same grouping $\mathrm{A}$ and $\mathrm{B}$. This fact agrees with the tensile and flexural behaviours, which did not reveal significant changes in fibre-matrix compatibility after treatment.
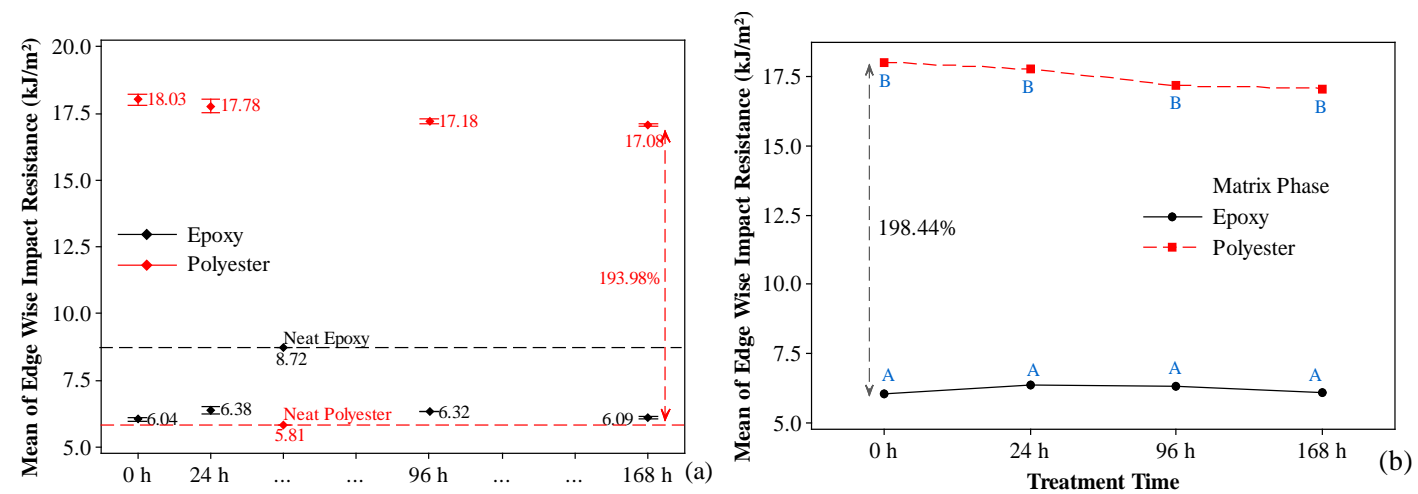

Figure 2. (a) Impact resistance values for coir fibre composites and neat matrices. (b) Second order interaction effect plot for the impact resistance. 

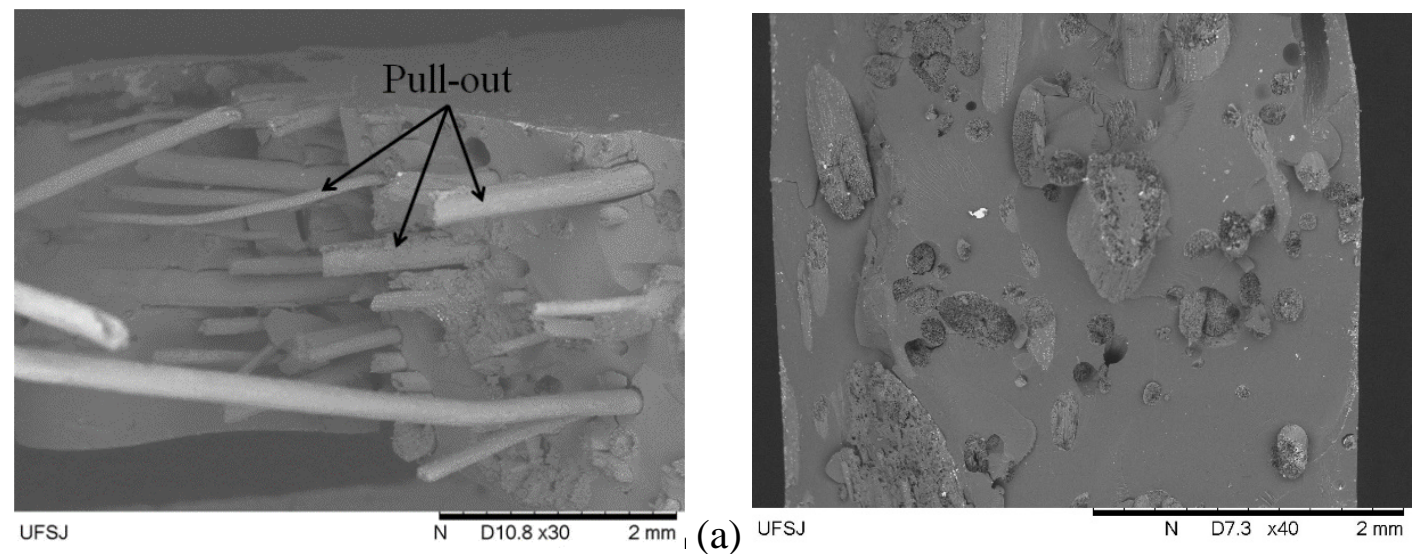

Figure 8. SEM images of the fractured surface of: (a) polyester and (b) epoxy composite after impact test.

\section{CONCLUSIONS}

The conclusions are described as follows:

i. A slight increase in coir fibre density of as a function of the treatment time was noted, being attributed to $\mathrm{Na}+$ ions, which are able to enlarge smaller pores contributing to open the cellular structure. The treatment solution did not provide a significant increase in fibre roughness, as observed by the SEM images. The treatment time factor did not affect the tensile strength of the fibres; however, the modulus of elasticity was substantially increased.

ii. Coir fibre reinforced composites achieved enhanced stiffness and reduced strength when compared to the polymer in pristine condition. The epoxy composites achieved higher tensile and flexural strength while the polyester composites obtained a higher tensile and flexural modulus. It is noteworthy, the polymer matrices obtained similar performance, revealing that the matrix phase substantially affects the mechanical properties of short-random coir fibre composites.

iii. The alkaline treatment did not affect the mechanical strength of the composites due to the presence of fibre pull-out mechanism. Enhanced tensile and flexural moduli were obtained when the treatment time increased at 96 or 168 hours levels.

iv. A higher impact resistance of polyester composites was attributed to the poor adhesion at the fibre/matrix interface.

Finally, although the proposed treatment is not as strong as the traditional one with sodium hydroxide, it proved to be feasible and efficient in increasing the coir fibre stiffness and its corresponding composites, besides being less harmful to the environment after disposal.

\section{ACKNOWLEDGEMENTS}

The authors would like to thank CAPES (MSc scholarship), CNPq (PP-306767/2016-3) and FAPEMIG (PPM-00075-17) for the financial support provided.

\section{REFERENCES}

[1] Brahmakumar, M., Pavithran, C. and Pillai, R.M., 'Coconut fibre reinforced polyethylene composites: Effect of natural waxy surface layer of the fibre on fibre/matrix interfacial bonding and strength of composites', Compos. Sci. Technol. 65 (2005) 563-569.

[2] Monteiro, S.N., Terrones, L.A.H. and D'Almeida, J.R.M., 'Mechanical performance of coir fiber/polyester composites', Polym. Test. 27 (2008) 591-595.

[3] Ramesh, M., Palanikumar, K. and Reddy, K.H., 'Plant fibre based bio-composites: Sustainable 
and renewable green materials', Renew. Sustain. Energy Rev. 79 (2017) 558-584.

[4] Ku, H., Wang, H., Pattarachaiyakoop, N. and Trada, M., 'A review on the tensile properties of natural fiber reinforced polymer composites', Compos. Part B Eng. 42 (2011) 856-873.

[5] Thakur, V.K. and Thakur, M.K., 'Processing and characterization of natural cellulose fibers/thermoset polymer composites', Carbohydr. Polym. 109 (2014) 102-117.

[6] Abdul Khalil, H.P.S., Bhat, A.H. and Ireana Yusra, A.F., 'Green composites from sustainable cellulose nanofibrils: A review', Carbohydr. Polym. 87 (2012) 963-979.

[7] Malkapuram, R., Kumar, V. and Singh Negi, Y., 'Recent development in natural fiber reinforced polypropylene composites', J. Reinf. Plast. Compos. 28 (2009) 1169-1189.

[8] Harish, S., Michael, D.P., Bensely, A., Lal, D.M. and Rajadurai, A., 'Mechanical property evaluation of natural fiber coir composite', Mater. Charact. 60 (2009) 44-49.

[9] Ezekiel, N., Ndazi, B., Nyahumwa, C. and Karlsson, S., 'Effect of temperature and durations of heating on coir fibers', Ind. Crops Prod. 33 (2011) 638-643.

[10] Akil, H.M., Omar, M.F., Mazuki, A.A.M., Safiee, S., Ishak, Z.A.M. and Abu Bakar, A., 'Kenaf fiber reinforced composites: A review', Mater. Design. 32 (2011) 4107-4121.

[11] Lecompte, T., Perrot, A., Subrianto, A., Le Duigou, A. and Ausias, G., 'A novel pull-out device used to study the influence of pressure during processing of cement-based material reinforced with coir', Constr. Build. Mater. 78 (2015) 224-233.

[12] Van Dam, J.E.G., Van Den Oever, M.J.A., Teunissen, W., Keijsers, E.R.P. and Peralta, A.G., 'Process for production of high density/high performance binderless boards from whole coconut husk. Part 1: Lignin as intrinsic thermosetting binder resin', Ind. Crops Prod. 19 (2004) 207-216.

[13] Saw, S.K., Sarkhel, G. and Choudhury, A., 'Surface modification of coir fibre involving oxidation of lignins followed by reaction with furfuryl alcohol: Characterization and stability', Appl. Surf. Sci. 257 (2011) 3763-3769.

[14] Rahman, M.M. and Khan, M.A., 'Surface treatment of coir (Cocos nucifera) fibers and its influence on the fibers' physico-mechanical properties', Compos. Sci. Technol. 67 (2007) 2369-2376.

[15] Geethamma, V.G., Thomas Mathew, K., Lakshminarayanan, R. and Thomas, S., 'Composite of short coir fibres and natural rubber: effect of chemical modification, loading and orientation of fibre', Polymer. 39 (1998) 1483-1491.

[16] Silva, G.G., De Souza, D.A., Machado, J.C. and Hourston, D.J., 'Mechanical and thermal characterization of native brazilian coir fiber', J. Appl. Polym. Sci. 76 (2000) 1197-1206.

[17] Zhang, L. and Hu, Y., 'Novel lignocellulosic hybrid particleboard composites made from rice straws and coir fibers', Mater. Design. 55 (2014) 19-26.

[18] Nam, T.H., Ogihara, S., Tung, N.H. and Kobayashi, S., 'Effect of alkali treatment on interfacial and mechanical properties of coir fiber reinforced poly(butylene succinate) biodegradable composites', Compos. Part B Eng. 42 (2011) 1648-1656.

[19] Mir, S.S., Nafsin, N., Hasan, M., Hasan, N. and Hassan, A., 'Improvement of physicomechanical properties of coir-polypropylene biocomposites by fiber chemical treatment', Mater. Design. 52 (2013) 251-257.

[20] Kumar, S.M.S., Duraibabu, D. and Subramanian, K., 'Studies on mechanical, thermal and dynamic mechanical properties of untreated (raw) and treated coconut sheath fiber reinforced epoxy composites', Mater. Design. 59 (2014) 63-69.

[21] Rout, J., Misra, M., Tripathy, S.S., Nayak, S.K. and Mohanty, A.K., 'The influence of fibre treatment on the performance of coir - polyester composites', Compos. Sci. Technol. 61 (2001) 1303-1310.

[22] Fiore, V., Di Bella, G. and Valenza, A., 'The effect of alkaline treatment on mechanical properties of kenaf fibers and their epoxy composites', Compos. Part B Eng. 68 (2015) 14-21.

[23] Obi Reddy, K., Uma Maheswari, C., Shukla, M., Song, J.I. and Varada Rajulu, A., 'Tensile and structural characterization of alkali treated Borassus fruit fine fibers', Compos. Part B Eng. 44 (2013) 433-438.

[24] $\mathrm{Gu}, \mathrm{H} .$, 'Tensile behaviours of the coir fibre and related composites after $\mathrm{NaOH}$ treatment', Mater. Design. 30 (2009) 3931-3934.

[25] Fiore, V., Scalici, T., Nicoletti, F., Vitale, G., Prestipino, M. and Valenza, A., 'A new eco- 
friendly chemical treatment of natural fibres: Effect of sodium bicarbonate on properties of sisal fibre and its epoxy composites', Compos. Part B Eng. 85 (2016) 150-160.

[25] ASTM D3822 - 12, Standard Test Method for Tensile Properties of Single Textile Fibers 1, (2012) 1-10.

[26] ASTM D276 - 12, Standard Test Methods for Identification of Fibers in Textiles, Astm. (2012) $1-14$.

[27] ASTM International, Standard test method for tensile properties of plastics, ASTM Int. 8 (2014) 46-58.

[28] ASTM D790-15, Standard Test Methods for Flexural Properties of Unreinforced and Reinforced Plastics and Electrical Insulating Materials. D790, (2015) 1-12.

[29] P.M. Materials, Standard Test Method for Determining the Charpy Impact Resistance of Notched Specimens of Plastics 1, (2010) 1-17.

[30] ASTM D3039/D3039M - 14, Standard, Standard Test Method for Tensile Properties of Polymer Matrix Composite Materials1, (2014) 1-13.

[31] Van de Weyenberg, I., Chi Truong, T., Vangrimde, B. and Verpoest, I., 'Improving the properties of UD flax fibre reinforced composites by applying an alkaline fibre treatment', Compos. Part A Appl. Sci. Manuf. 37 (2006) 1368-1376.

[32] Gwon, J.G., Lee, S.Y., Doh, G.H. and Kim, J.H., 'Characterization of Chemically Modified Wood Fibers Using FTIR Spectroscopy for Biocomposites', J. Appl. Polym. Sci. 116 (2010) 3212-3219.

[33] Muensri, P., Kunanopparat, T., Menut, P. and Siriwattanayotin, S., 'Effect of lignin removal on the properties of coconut coir fiber/wheat gluten biocomposite', Compos. Part A Appl. Sci. Manuf. 42 (2011) 173-179.

[34] Yan, L., Chouw, N., Huang, L. and Kasal, B., 'Effect of alkali treatment on microstructure and mechanical properties of coir fibres, coir fibre reinforced-polymer composites and reinforcedcementitious composites', Constr. Build. Mater. 112. 112 (2016) 168-182.

[35] Oliveira, L.A., Santos, J.C., Panzera, T.H., Freire, R.T., Vieira, L.M.G. and Scarpa, F., 'Evaluation of Hybrid-Short-Coir-Fibre-Reinforced Composites via Full Factorial Design', Compos. Struct. (2018).

[36] Ebnesajjad, S. and Ebnesajjad, C. 'Surface treatment of materials for adhesive bonding', 2014.

[37] De Albuquerque, A.C., Joseph, K., De Carvalho, H.L. and D’Almeida, J.R.M., 'Effect of wettability and ageing conditions on the physical and mechanical properties of uniaxially oriented jute-roving-reinforced polyester composites', Compos. Sci. Technol. 60 (2000) 833844.

[38] Dassios, K.G., 'A review of the Pull-Out Mechanism in the Fracture of Brittle- Matrix FibreReinforced Composites', Adv. Compos. Lett. 16 (2007) 17-24.

[39] Wang, C., Ji, X., Roy, A., Silberschmidt, V.V. and Chen, Z., 'Shear strength and fracture toughness of carbon fibre/epoxy interface: effect of surface treatment', Mater. Design. 85 (2015) 800-807. 